MS. ELENA PIANO (Orcid ID : 0000-0002-4685-7240)

DR. THOMAS MERCKX (Orcid ID : 0000-0002-6195-3302)

DR. KRISTIEN I. BRANS (Orcid ID : 0000-0002-0464-7720)

DR. MAXIME DAHIREL (Orcid ID : 0000-0001-8077-7765)

DR. FREDERIK HENDRICKX (Orcid ID : 0000-0002-1176-0318)

Article type : Primary Research Articles

\title{
Urbanization drives cross-taxon declines in abundance and diversity at multiple spatial scales
}

Running title: Urbanization impacts abundance and diversity

Elena Piano ${ }^{* 1,2}$, Caroline Souffreau ${ }^{3}$, Thomas Merckx ${ }^{4,5}$, Lisa F. Baardsen ${ }^{6}$, Thierry Backeljau ${ }^{1,6}$, Dries Bonte $^{7}$, Kristien I. Brans ${ }^{3}$, Marie Cours ${ }^{8}$, Maxime Dahirel1 ${ }^{7,9}$, Nicolas Debortoli ${ }^{10}$, Ellen Decaestecker ${ }^{11}$, Katrien De Wolf ${ }^{1,12}$, Jessie M.T. Engelen ${ }^{3}$, Diego Fontaneto ${ }^{13}$, Andros T. Gianuca ${ }^{3,14}$, Lynn Govaert ${ }^{3,15,16}$, Fabio T. T. Hanashiro ${ }^{3}$, Janet Higuti ${ }^{17}$, Luc Lens ${ }^{7}$, Koen Martens ${ }^{8}, 18$, Hans Matheve ${ }^{7}$, Erik Matthysen ${ }^{6}$, Eveline Pinseel ${ }^{19,20}$, Rose Sablon ${ }^{1}$, Isa Schön ${ }^{8,21}$, Robby Stoks ${ }^{22}$, Karine Van Doninck ${ }^{10}$, Hans Van Dyck ${ }^{4}$, Pieter Vanormelingen ${ }^{19}$, Jeroen Van Wichelen ${ }^{19,23}$, Wim Vyverman ${ }^{19}$, Luc De Meester ${ }^{+3}$ \& Frederik Hendrickx ${ }^{+1,7}$

${ }^{1}$ Royal Belgian Institute of Natural Sciences, OD Taxonomy and Phylogeny, Brussels, Belgium 
${ }^{2}$ Department of Life Sciences and System Biology, University of Turin, Turin, Italy

${ }^{3}$ Laboratory of Aquatic Ecology, Evolution and Conservation, KU Leuven, Leuven, Belgium

${ }^{4}$ Behavioural Ecology and Conservation Group, Biodiversity Research Centre, Earth and Life Institute, UCLouvain, Louvain-la-Neuve, Belgium

${ }^{5}$ Department of Ecology and Genetics, University of Oulu, Oulu, Finland

${ }^{6}$ Evolutionary Ecology Group, University of Antwerp, Antwerp, Belgium

${ }^{6}$ Terrestrial Ecology Unit, Biology Department, Ghent University, Ghent, Belgium

${ }^{8}$ Royal Belgian Institute of Natural Sciences, OD Natural Environment, Brussels, Belgium

${ }^{9}$ Ecosystems, Biodiversity and Evolution Unit, Université de Rennes 1 (CNRS), Rennes, France

${ }^{10}$ Laboratory of Evolutionary Genetics and Ecology, URBE, NAXYS, University of Namur, Namur, Belgium

${ }^{11}$ Laboratory of Aquatic Biology, KU Leuven Kulak, Kortrijk, Belgium.

${ }^{12}$ Institute of Tropical Medicine, Antwerp, Belgium

${ }^{13}$ National Research Council, Water Research Institute, CNR-IRSA, Verbania-Pallanza, Italy

${ }^{14}$ Department of Ecology, Centro de Biociências, Universidade Federal do Rio Grande do Norte, Natal, Rio Grande do Norte, Brazil

${ }^{15}$ Swiss Federal Institute of Aquatic Science and Technology, Department of Aquatic Ecology, Dübendorf, Switzerland

16 Department of Evolutionary Biology and Environmental Studies, University of Zurich, Zürich, Switzerland

17 Centre of Research in Limnology, Ichthyology and Aquaculture/PEA, State University of Maringá, Maringá, Brazil.

${ }^{18}$ Laboratory of Limnology, Biology Department, Ghent University, Ghent, Belgium

${ }^{19}$ Laboratory of Protistology \& Aquatic Ecology, Biology Department, Ghent University, Ghent, Belgium

${ }^{20}$ Research Department, Meise Botanic Garden, Meise, Belgium 
${ }^{21}$ Zoology Research Group, University of Hasselt, Hasselt, Belgium

${ }^{22}$ Evolutionary Stress Ecology and Ecotoxicology, KU Leuven, Leuven, Belgium

${ }^{23}$ Aquatic Management, Research Institute for Nature and Forest (INBO), Brussels, Belgium

*=Corresponding author: elena.piano@unito.it

$+=$ Shared senior authorship 


\section{Abstract}

The increasing urbanization process is hypothesized to drastically alter (semi-)natural environments with a concomitant major decline in species abundance and diversity. Yet, studies on this effect of urbanization, and the spatial scale at which it acts, are at present inconclusive due to the large heterogeneity in taxonomic groups and spatial scales at which this relationship has been investigated among studies. Comprehensive studies analysing this relationship across multiple animal groups and at multiple spatial scales are rare, hampering the assessment of how biodiversity generally responds to urbanization. We studied aquatic (cladocerans), limnoterrestrial (bdelloid rotifers) and terrestrial (butterflies, ground beetles, ground- and web spiders, macro-moths, orthopterans and snails) invertebrate groups using a hierarchical spatial design wherein three local-scale $(200 \mathrm{~m} \times 200 \mathrm{~m})$ urbanization levels were repeatedly sampled across three landscape-scale $(3 \mathrm{~km} \times 3 \mathrm{~km})$ urbanization levels. We tested for local and landscape urbanization effects on abundance and species richness of each group, whereby total richness was partitioned into the average richness of local communities and the richness due to variation among local communities. Abundances of the terrestrial active dispersers declined in response to local urbanization, with reductions up to $85 \%$ for butterflies, while passive dispersers did not show any clear trend. Species richness also declined with increasing levels of urbanization, but responses were highly heterogeneous among the different groups with respect to the richness component and the spatial scale at which urbanization impacts richness. Depending on the group, species richness declined due to biotic homogenization and/or local species loss. This resulted in an overall decrease in total richness across groups in urban areas. These results provide strong support to the general negative impact of urbanization on abundance and species richness within habitat patches and highlight the importance of considering multiple spatial scales and taxa to assess the impacts of urbanization.

Keywords: biodiversity; biotic homogenization; diversity partitioning; insect decline; land use; spatial scale; urban ecology 


\section{INTRODUCTION}

The conversion of natural and rural land to urban environments increased drastically worldwide over the last 30 years, with urban land cover expected to be tripled from 2000 to 2030 (Seto, Güneralp \& Hutyra 2012). Urbanization drives global environmental change and is currently one of the main anthropogenic impacts (Parris 2016) with expected drastic consequences on biodiversity and ecosystem processes. Urbanization-associated changes in community structure can result from several mechanisms (Rebele, 1994; Seto, Sánchez-Rodríguez \& Fragkias, 2010), which act at multiple spatial scales (Shochat, Warren, Faeth, McIntyre \& Hope, 2006; Shochat et al., 2010) and are strongly habitat-dependent (Hill et al., 2017). Ecological effects are due to substantial changes in local abiotic environmental conditions (e.g. high levels of nutrients, pollution, and imperviousness) (Parris, 2016), and to landscape structure (e.g. reduced size and connectivity and increased temporal turnover of habitat patches) (McDonnell, et al. 1997; Parris, 2016).

Several studies investigated relationships between urbanization and two important determinants of ecosystem functioning i.e. the abundance and/or diversity of species. Yet, their results are surprisingly equivocal, as negative relationships (Chace \& Walsh, 2006; Lagucki, Burdine \& McCluney, 2017; Niemelä \& Kotze, 2009; Ramirez-Restrepo \& Macgregor-Fors, 2017; Saari et al., 2016), no relationship (Christie \& Hochuli, 2009), as well as positive relationships (Hill et al., 2017; McKinney, 2008; Shochat et al., 2010), are reported. These heterogeneous results suggest that the effect of increasing urbanization might strongly depend on the spatial scale and taxon for which it is assessed (Concepción et al., 2015; Egerer et al., 2017; McKinney, 2008; Philpott et al., 2014).

First, the direction and magnitude of changes in species diversity in response to an environmental driver may strongly depend on the spatial scale at which species diversity is measured (Chase \& Knight, 2013). For instance, urbanization may filter out species that are not pre-adapted to urban conditions, with a consequent decrease in abundance or diversity at small (local) spatial scales (Bates et al., 2011; Piano et al., 2017). Alternatively, the loss of species that are less adapted to urban environments could be (over)compensated by an increase of species that are efficient in exploiting urban resources, including exotic taxa (McKinney, 2006; Menke et al., 2011; Sattler, Obrist, Duelli \& Moretti, 2011). Both phenomena may cause biotic homogenization if local 
communities are colonized by the same species, increasing in turn the compositional similarity of urban species assemblages and, consequently, reducing species richness of urban areas at large spatial scales (Knop, 2016; McKinney, 2006; Morelli et al., 2016).

Second, organisms may react to urbanization at different spatial scales (Concepción, Moretti, Altermatt, Nobis \& Obrist, 2015; Fahrig, 2013; Merckx et al., 2018; Soininen, McDonald \& Hillebrand, 2007; Wiens, 1989). Species traits, such as dispersal capacity, affect how organisms perceive and respond to their environment (Wiens, 1989), and hence, how species are spatially distributed (Finlay, Esteban, Brown, Fenchel \& Hoef-Emden, 2006). Thus, urbanization effects may remain undetected if not assessed at relevant spatial scales (Jackson \& Fahrig, 2015; Turrini \& Knop, 2015).

A comprehensive assessment of the overall effects of urbanization on species communities is unlikely to be resolved by studying single taxa and single spatial scales. Instead, insights into general patterns of abundance and diversity change should be obtained by integrating data over multiple animal groups, while uncoupling the spatial scales at which urbanization and species richness are measured.

Here, we analysed data on abundance and species richness data of one limno-terrestrial (bdelloid rotifers), one aquatic (cladocerans) and seven terrestrial (butterflies, ground beetles, ground- and web spiders, macro-moths, orthopterans and snails) animal groups sampled along replicated urbanization gradients in Belgium. More specifically, we sampled communities according to a hierarchically nested sampling design, in which three local-scale urbanization levels were repeatedly sampled across the same three urbanization levels at the landscape scale (Merckx et al. 2018). This sampling design allowed us to partition the total species richness ( $\gamma$-diversity) into richness within local communities ( $\alpha$-diversity) and richness due to variation in species composition among local communities ( $\beta$-diversity), and to relate these to both local and landscape-scale urbanization levels. We explored (i) if, and in which direction, local and landscape-scale urbanization affect total abundance; (ii) if local and landscape-scale urbanization affect species richness within habitat patches, and if so at which spatial scale; and (iii) to what extent these responses are consistent across animal groups. 


\section{MATERIALS AND METHODS}

\section{Sampling area and design}

Sampling was conducted in Belgium, within a polygon of $8140 \mathrm{~km}^{2}$, encompassing the cities of Brussels, Antwerp and Ghent. It is a densely populated region (average human population density of Belgium: 371 inhabitants $/ \mathrm{km}^{2}$, IBZ, 2018) that is composed of urban areas embedded within a semi-natural and agricultural matrix. Because urbanization encompasses a range of factors that alter the physical environment and landscape characteristics, we defined the percentage of built-up area $(\% \mathrm{BU})$ as a proxy for urbanization and this was assessed with a GIS software using an objectoriented reference map of Flanders as a vectorial layer (LRD, 2013). This layer included the precise contours of all buildings, while roads and parking infrastructures were excluded. To test effects of urbanization at the landscape scale, we selected 27 plots (i.e. squares of $3 \mathrm{~km} \times 3 \mathrm{~km}$ ), among which nine located in areas with low urbanization (low: $0 \%-3 \% \mathrm{BU}$ ), nine plots in areas with intermediate urbanization (intermediate: $5 \%-10 \% \mathrm{BU}$ ) and nine in highly urbanized areas (high: $>15 \% \mathrm{BU}$ ) (Figure 1). The latter encompassed city centres. Given that only buildings are considered for the calculation of $\% \mathrm{BU}$, values of $15 \%$ can be considered highly urbanized. We first selected plots within this highest $\% \mathrm{BU}$ category that were approximately equidistant from each other within the study area. Next, plots of the intermediate and lowest urbanization categories were selected within 10-25 km of the highly urbanized plots. This plot selection strategy guaranteed that plots within the same urbanization category are evenly distributed across the study area and ensured a minimal spatial autocorrelation of plot urbanization levels. Across plots, \%BU was positively correlated with the amount of other impervious substrates such as roads and artificial constructions (for example bridges, viaducts, locks, ...) $\left(r_{\mathrm{S}}=0.94 ; P<0.0001\right)$ and negatively correlated with the area of semi-natural habitat $\left(r_{\mathrm{S}}=-0.85 ; P<0.0001\right)$ (Figure $\left.\mathrm{S} 1\right)$, thus representing a reliable proxy of urbanization. To investigate effects of local-scale urbanization, each plot was divided into local subplots of $200 \mathrm{~m} \times 200 \mathrm{~m}$, which were classified into urbanization categories using identical \%BU thresholds as used at plot level. Within each plot, we then selected one subplot of each urbanization category (i.e. low, intermediate and high) for a total of 81 sampling sites (i.e. 9 plots $\times 3$ landscape-scale urbanization levels $\times 3$ local-scale urbanization levels) (Figure 1). This selection was random within the constraints imposed by the availability of targeted habitats (e.g. pond, grassland, woodland), accessibility and the permission to sample. 
This setup guaranteed that urbanization at landscape and local scales are uncorrelated and, hence, that urbanization effects at both scales, and their interaction, could be tested simultaneously. The same sampling design was applied to all taxa, and all sampling was based on the same set of plots (landscape-level of urbanization). At the local level too, the same sampling design was implemented across organism groups, but the choice of specific subplots featuring a given level of local urbanization within each plot could differ between groups as sampling sites suitable for all groups were not always present within the same $200 \mathrm{~m}$ x $200 \mathrm{~m}$ subplot. Except for web spiders and macro-moths, all, or nearly all, of the 81 subplots were sampled for each animal group (see Sampling methods).

\section{Sampling methods}

\section{Ground beetles and ground spiders}

Ground beetles and ground-dwelling spiders were sampled with pitfall traps from half of April till the end of June 2013. Within each subplot, two pitfall traps (diameter $8 \mathrm{~cm}$ ) were installed $(25-50$ $\mathrm{m}$ apart) and emptied every two weeks for a total of six sampling sessions. Because four traps were lost during the last sampling campaign (end of June), data from the last sampling session were not used for analysis. Pitfall traps were placed consistently in grassy-herbaceous vegetation such as road verges, park grasslands and grasslands at the different subplot urbanization levels. Samples were preserved in $4 \%$ formalin and sorted in the laboratory. Data from both pitfall samples per site and the different sampling dates were pooled and treated as a single sampling unit. All ground beetles and adult spiders were counted and identified to species level (Boeken, 2002; Duff, 2016; Roberts, 2009). Juvenile spiders were excluded from the final dataset since they could only be identified to genus level.

\section{Web spiders}

Web spiders were sampled by hand between the $27^{\text {th }}$ of August and the $5^{\text {th }}$ of October 2014 in 62 out of the 81 subplots. One landscape (3 subplots) was sampled per day. Each subplot was explored by the same two persons for about 4.5 hours per person. Spiders were detected by looking for their webs and each subplot was completely explored searching for orb-weaving spiders until no new individual could be found after $15 \mathrm{~min}$. Rainy days were avoided as spiders 
may be less likely to build webs and are thus less detectable. Every encountered spider was caught and stored in $70 \%$ ethanol. Identification was performed under a stereomicroscope to species level (Roberts, 2009). Juveniles were excluded from the final dataset since they could only be identified to genus level. Spiders captured according to this methodology are further referred to as 'web spiders' to distinguish them from the 'ground spiders' that were captured by pitfall traps (see section Ground beetles and ground spiders).

\section{Macro-moths}

Sampling was restricted to a set of nine plots, three of each plot urbanization category, and performed in woodland with Jalas type bait traps in three sampling sessions, which started on the $30^{\text {th }}-31^{\text {st }}$ of July 2014 (first session), $13^{\text {th }}-14^{\text {th }}$ of August 2014 (second session) and $30^{\text {th }}-31^{\text {st }}$ of March and $1^{\text {st }}$ of April 2015 (third session). Traps were emptied on $3^{\text {rd }}-4^{\text {th }}$ of August 2014 (first session), $2^{\text {nd }}-3^{\text {rd }}$ of September 2014 (second session) and $24^{\text {th }}-25^{\text {th }}-26^{\text {th }}$ of April 2015 (third session). Traps were baited with sugar-saturated wine and sampled individuals were poisoned with chloroform within the traps. Individuals were counted and identified to species level (Manley, 2010), except for two species pairs: Mesapamea secalis/secalella and Hoplodrina blanda/octogenaria.

\section{Butterflies and orthopterans}

Butterflies and orthopterans (grasshoppers and bush crickets) were sampled along standard transects in three sampling sessions performed in 2014, from July to early September. Walks of 20 minutes were performed in each of the 81 subplots in grasslands during the warmest hours of the day, i.e. between 10 a.m. and 4 p.m. avoiding cloudy and rainy days. Butterflies were sampled with visual counts along a transect ('Pollard walk', Pollard \& Yates, 1993), with occasional netting of individuals when needed for species identification. All individuals were identified in the field to the species level following Bink (1992). Orthopterans were sampled through auditive counts with occasional visual inspection of individuals.

\section{Snails}

Snails were sampled by hand during visual search along transects. Each subplot was visited once from April to July 2014 and additional samplings were performed in 2015. Snails were searched along a ca. 150-200 m transect in an area of $50 \mathrm{~m}$ at both sides. Individuals were mainly searched 
in the most appropriate habitats, i.e. (i) at the bottom of/on herbs, shrubs and trees, (ii) under branches, piled wood, cardboard and construction/demolition materials, and (iii) along/on fences and walls.

\section{Bdelloid rotifers}

Communities of bdelloid rotifers were sampled by collecting lichen patches of the genus Xanthoria, for which bdelloid rotifer communities have been previously studied in Europe (Fontaneto, Westberg \& Hortal, 2011). Suitable Xanthoria patches could be found in all but one subplot. Sampling was performed between June and July 2013. The selection of the lichen was haphazard: the first lichen patch encountered in each subplot was collected. Dry lichen thalli between 3 and $10 \mathrm{~cm}^{2}$ were cut from the substrate with a knife and kept in paper bags. For each lichen sample, an area of $2.5 \mathrm{~cm}^{2}$ was hydrated with distilled water in a plastic petri dish. All active bdelloid rotifers that recovered from dormancy in the following four hours after hydration were sorted and identified to species level (Donner, 1965). Previous studies on bdelloid rotifers in these lichens (Fontaneto et al., 2011) revealed that animals start recovering between 10 and 40 minutes after hydration of the sample and that no more bdelloid rotifers are recovered after four hours. The very few dormant stages still found in the sample that did not recover after that time were considered dead and excluded from the analyses.

\section{Cladocerans}

Water samples were collected from ponds using a tube sampler (length $=1.85 \mathrm{~m}$; diameter $=75$ $\mathrm{mm}$; Gianuca et al. 2018). One pond was selected in each of the 81 selected subplots. Sampling was performed once for each pond and all sampling was performed in the period from $29^{\text {th }}$ of May to the $10^{\text {th }}$ of July 2013. In each pond, eight sampling locations were selected using a predefined grid, assuring that different microhabitats (shallow and deeper zone, different locations with respect to wind direction) were represented to a similar extent. On each sample location, the exact place to be sampled was chosen in a random way, regardless of the presence of macrophytes. At each of the eight locations, $12 \mathrm{~L}$ of water was collected, resulting in a total of $96 \mathrm{~L}$ per pond. The tube sample integrated the entire water column, but resuspension and subsequent sampling of bottom material was avoided. For each pond, $40 \mathrm{~L}$ of water was filtered through a $64 \mu \mathrm{m}$ conical net. The sample was then collected in a $60 \mathrm{~mL}$ vial and fixed with formalin (4\%). Additional sampling was performed with a sweep-net $(64 \mu \mathrm{m}$ net) and preserved in the same way. These 
additional samples served to guarantee sufficiently extensive sampling to reconstruct an as complete as possible species list. Individuals in standardized subsamples were identified and counted; entire subsamples were counted until at least 300 individuals were identified and no new species was found in the last 100 specimens. Samples containing less than 300 individuals were counted completely, and the additional qualitative samples for those ponds were screened for additional species. Species identification was based on Flößner (2000). Daphnia longispina, Daphnia galeata and Daphnia hyalina were combined in the Daphnia longispina complex due to the morphological similarities and possible hybridization between the species. Detailed information on the sampling and identification of zooplankton are reported in Brans et al. (2017) and Gianuca et al. (2018). Densities were calculated as number of individuals per L of the original sample.

\section{Abundance data and analysis}

The total number of sampled/observed individuals in each sample/transect was used as an estimate for the abundance of each group in each subplot. For cladocerans, abundance data are based on the total number of individuals in a standardized volume of $40 \mathrm{~L}$. Differences in abundances in response to local (subplot) and landscape (plot) scale urbanization levels were tested by means of a Generalized Linear Mixed Model (GLMM) for each of the investigated groups. Local- (subplot) and landscape-scale (plot) urbanization levels and their interaction were specified as fixed factors. As each plot included three subplots, one for each urbanization category, a plot identifier (PlotID) was incorporated as a random factor to account for the spatial dependency of subplots within the same plot. Abundance data were assumed to be Poisson distributed and the sample variance instead of the theoretical variance was used to account for potential overdispersion (Agresti et al. 1996). Analyses were conducted with PROC GLIMMIX in SAS ${ }^{\circledR} 9.4$ (SAS Institute Inc. 2013). We further tested for a cross-group response in total abundance of individuals at both local- and landscape-scale urbanization with the non-parametric Page test (Hollander \& Wolfe, 1973). This test accounts for the ordering of the urbanization levels (low - intermediate - high), with the nine groups specified as blocks. $P$-values were based on permutations within blocks and obtained from StatXact v5 (C) Cytel Software, 2001).

\section{Species richness data and analysis}

Effect of local- and landscape-scale urbanization on total species richness 
We first assessed general responses in total species richness due to local- and landscape-scale urbanization by means of sample-based accumulation curves, which express the cumulative number of species when samples from a particular local- or landscape-scale urbanization category are added at random. Given that we aim at identifying responses in total $(\gamma)$ species richness only, we restricted the analysis to five local/landscape-scale urbanization combinations. More specifically, we compared sample-based accumulation curves between: (i) subplots with low urbanization in plots with low urbanization (low end urbanization at both spatial scales); (ii) highly urbanized subplots in highly urbanized plots (high end urbanization at both spatial scales); (iii) plots with low urbanization regardless of the degree of local urbanization; (iv) highly urbanized plots regardless of the degree of local urbanization and (v) all samples regardless of the degree of local- and landscape-scale urbanization. This latter combination of samples thus represents a mix of plots and subplots with low and high urbanization. Settings (i) - (iii) - (v) (iv) - (ii) represent a gradient of urbanization levels integrating both spatial scales.

For each animal group, we tested if total species richness declined significantly with increasing local/landscape-scale urbanization level by means of the ordered heterogeneity test through the $r_{\mathrm{S}} P_{\mathrm{c}}$ statistic (Rice \& Gaines, 1994), which combines the statistical evidence of differences between sample means with their rank order. More precisely, we first tested for differences in species richness among urbanization categories by comparing the observed average absolute differences in total species richness for a total of nine samples (corresponding to the lowest sample size of the five local/landscape-scale combinations) with those obtained by random shuffling samples across these five combinations (mobr package 1.0; Xiao, McGlinn, May \& Oliver, 2018 in R 3.4.2 (R Development Core Team, 2017)). We then multiplied the complement of the obtained $P$-value $\left(P_{\mathrm{c}}\right)$ with the Spearman Rank order correlation $\left(r_{\mathrm{S}}\right)$ between species richness and increasing urbanization level to obtain the $r_{\mathrm{S}} P_{\mathrm{c}}$ statistic.

Next, we tested for a cross-group response in total species richness among these five urbanization categories with the non-parametric Page test (Hollander \& Wolfe, 1973), specifying the nine groups as blocks. $P$-values were based on permutations within blocks and obtained from StatXact v5 (C) Cytel Software, 2001).

Effect of local-and landscape-scale urbanization on species richness components 
To gain more insights into the spatial scale at which species richness of each group is most strongly affected by urbanization, we partitioned the total species richness observed at each localor landscape-scale urbanization level into its underlying components. We used a diversity partitioning approach whereby the total diversity at larger spatial scales $(\gamma)$ is decomposed into its average local species richness $(\bar{\alpha})$ and species richness due to variation between local communities $(\beta)$. As a measure of variation in species composition between local communities, we calculated both the proportional differences in species composition of the local communities compared to the total species community $\left(\bar{\beta}_{P}=\gamma / \bar{\alpha}\right)$ as well as additive variation $\left(\bar{\beta}_{A}=\gamma-\bar{\alpha}\right)$ as these measures of $\beta$-diversity can be calculated and compared at multiple hierarchical spatial scales (Lande, 1996; Crist, Veech, Gering \& Summerville, 2003; Anderson et al., 2011). While $\bar{\beta}_{P}$ expresses how much the richness at plot (or regional) level increases compared to the richness at subplot (or plot) level, $\bar{\beta}_{A}$ expresses the absolute increase in number of species between these two sampling levels.

Effects of local-scale urbanization on species richness were assessed by comparing decomposed species richness values along a gradient of local-scale urbanization. This is a two-step procedure. First, we decomposed the total species richness $(\gamma)$ of all subplots belonging to the same urbanization level into the average species richness within subplots $(\bar{\alpha})$ and the average additive and proportional variation among subplots $\left(\beta_{\text {among }}\right)$, and we did so for each of the three levels of local urbanization (Figure 2a). Second, differences in these species richness components across urbanization levels were tested with a randomization test, by permuting samples over the three local-scale urbanization levels (McGlinn et al., 2019).

The effect of landscape-scale urbanization on species richness can be evaluated both within and between plots. For the former, we decomposed the total species richness within plots $\left(\gamma_{\text {within }}\right)$ into the average local species richness of the three subplots within a plot $(\alpha)$ and the additive and proportional variation between these communities $\left(\beta_{\text {within }}\right)$. For the latter, we decomposed the species richness across all plots $\left(\gamma_{\text {among }}\right)$ into the average species richness within a plot $\left(\gamma_{\text {within }}\right)$ and the additive and proportional variation in species richness among plots $\left(\beta_{\text {among }}\right)$ (Figure $2 \mathrm{~b}$ ). Differences in species richness along the urbanization gradient at both scales were tested with a randomization test, by permuting samples over the three landscape-scale urbanization levels (McGlinn et al., 2019).

Observed versus rarefied species richness 
Observed species richness is a composite measure and differences in this metric among samples may result from variation in (i) the number of individuals present at a particular site, (ii) the spatial aggregation of individuals of the same species, and (iii) the number and relative abundance of species in the species pool (i.e. the species abundance distribution or SAD) (He \& Legendre, 2002). We therefore also calculated rarefied species richness as the expected number of species for each diversity component for a standardized number of randomly selected individuals by means of individual-based rarefaction curves. By removing the effect of individual densities, differences in rarefied species richness provide more information on differences in the SAD between communities. At the regional $(\gamma)$ scale, we rarefied for each animal group to the number of individuals in the urbanization category that yielded the smallest sample size.

\section{Overall pattern across groups}

While the above analyses were performed separately for each group, we further tested for a significant change in the diversity components in response to the landscape- and local-scale urbanization gradients across groups by means of the non-parametric Page test (Hollander \& Wolfe, 1973) for both observed and rarefied richness values. The nine groups were specified as blocks and $P$-values were obtained from StatXact v5 (C) Cytel Software, 2001) based on permutations within blocks.

\section{RESULTS}

\section{Abundance}

Although we could not detect an overall decrease in total abundance across the investigated groups along the urbanization gradient at both the local (Page test; $P>0.05$ ) and landscape scale (Page test; $P>0.05$ ), increasing the local-scale (subplot) urbanization level significantly decreased the abundance of all the terrestrial arthropods (ground beetles, ground- and web spiders, butterflies and orthopterans), except for the macro-moths (Table 1, Figure 3). This decline was most substantial for orthopterans and butterflies, with a reduction in abundance of $67.4 \%$ and $85.5 \%$ respectively, in the most urbanized compared to the least urbanized subplots. Local-scale urbanization had a much stronger effect on abundance than landscape-scale urbanization, which showed no effects in any of the investigated groups. An additional synergistic effect of local and landscape-scale urbanization was only observed for butterflies, with abundance decreasing 
stronger along the local-scale urbanization gradient with increasing landscape-scale urbanization levels (Figure 3).

\section{Total species richness}

Sample-based accumulation curves showed a trend towards a slower accumulation of species at increasing local and/or regional urbanization levels for most of the investigated groups (Figure S2). Rarefying richness to a size of nine samples for each combination revealed decreases in total species richness for ground beetles, web spiders, macro-moths, butterflies and orthopterans $\left(r_{\mathrm{S}} P_{\mathrm{c}}<\right.$ 0.05; Figure 4a). A decline was also observed in total species richness across groups with increasing urbanization levels (Page-test; $P<0.001$ ). Samples originating from a mixture of high, intermediate and low urbanized plots and subplots had a lower species richness compared to those based on samples from subplots with low urbanization in plots with low urbanization only, indicating that plots consisting of a mosaic of subplots with low and high urbanization harbour fewer species across groups compared to plots with low urbanization (Page-test; $P=0.007$ ). Other pairwise comparisons between the urbanization categories were also significant (Page test; $P<$ 0.03), except for high local/landscape urbanization versus high landscape urbanization (Page test; $P=0.15)$ and low local/landscape urbanization versus low landscape urbanization (Page test; $P=$ $0.45)$.

We further tested if the decrease in species richness is higher for those groups that show a strong decrease in abundance, as this would indicate that the decrease in species richness is, at least partly, due to a lower sampling effect in urbanized landscapes. More precisely, we correlated the relative change in species richness in highly urbanized subplots in highly urbanized plots versus subplots with low urbanization in plots with low urbanization with the relative change in abundance (Figure 4b). Groups showing the strongest decrease in abundance (macro-moths, butterflies, orthopterans, ground beetles and ground spiders) showed a significant reduction in both local species richness (i.e. average species richness within subplots) $\left(r_{S}=0.95, P<0.001\right)$ and total species richness (i.e. species richness across subplots) $\left(r_{S}=0.69, P=0.04\right)$.

\section{Species richness decomposition}

High local- and landscape-level urbanization reduced total $(\gamma)$ species richness across the investigated groups by $7 \%$ and $14 \%$, respectively (Page test; $P=0.026$ and $P=0.003$, respectively; Figure 5; Table 2). Increased landscape-level urbanization also decreased average 
local $(\alpha)$ species richness by $14 \%$ (Page test; $P=0.047$ ), but did not result in a consistent change in species variation $(\beta)$ across the investigated groups (Figure 5; Table 2).

Group specific responses were highly heterogeneous, but, except for bdelloid rotifers and cladocerans, all groups showed a significantly negative response towards increasing local- and/or landscape-scale urbanization for at least one of the diversity components (Table 2). Increased local urbanization primarily decreased local $(\alpha)$ diversity of butterflies and orthopterans and decreased (additive) variation in species composition $\left(\beta_{A}\right)$ of ground beetles, snails and orthopterans. The effects of landscape-scale urbanization resulted in decreases in local diversity of web spiders and macro-moths, a decrease in variation among local communities within urbanized landscapes $\left(\beta_{A, \text { within }}\right)$ in macro-moths and a decrease in variation among urbanized landscapes $\left(\beta_{A, \text { among }}\right)$ in ground beetles, ground spiders and orthopterans. Positive relationships with increasing urbanization were observed in butterflies, showing positive responses in both proportional and additive variation in species composition among locally urbanized sites. A positive relationship with increasing urbanization was also observed for web spiders, with an increase in variation among urbanized landscapes $\left(\beta_{A, \text { among }}\right)$. Similar results were observed for cladocerans, which showed increasing local diversity within urbanized landscapes along the urbanization gradient.

Results obtained from rarefied richness roughly corresponded with the results of observed richness, but generally resulted in weaker urbanization effects at the $\alpha$ and $\gamma$ levels (Table 2b). For example, the effect of urbanization at local $(\alpha)$ scale was reduced for macro-moths, butterflies and orthopterans when considering rarefied compared to observed richness. In contrast to observed richness, there is no detectable across-group decline in rarefied total $(\gamma)$ diversity due to either local or landscape urbanization. Conversely, rarefying richness generally led to more negative effects of local urbanization levels on additive species variation $\left(\beta_{A}\right)$, with declines for six groups. Across-group analysis revealed that increasing levels of landscape urbanization led to an average decline in rarefied local $(\alpha)$ richness (Page test; $P=0.023$ ) and an increase in proportional variation in rarefied species richness (Page test; $P=0.011)$ within plots $\left(\beta_{P \text { within }}\right)$.

\section{DISCUSSION}


Urbanization is expected to inflict major impacts on biodiversity and ecosystem functioning, together with other large-scale anthropogenic disturbances, such as agricultural intensification and deforestation (Grimm et al., 2008; Shochat et al., 2010). Yet, studies show inconsistent responses that are likely attributed to differences in the examined groups, the spatial extent at which urbanization was assessed, the range of the urbanization gradient and the spatial scale at which the responses to urbanization are measured (Aronson et al., 2014; Faeth, Bang \& Saari, 2011; Marzluff, 2017; Saari et al., 2016). To account for variation in group- and scale-specific effects, we here integrate data from multiple groups and multiple spatial scales in a study sampling identical urbanization gradients and demonstrate that urbanization drives declines in the abundance for most investigated groups and species richness across the examined groups. In line with the previously reported heterogeneous patterns of biodiversity along urbanization gradients, we found that group-specific responses strongly depended on the spatial scale at which urbanization and species richness are assessed. Integrating data across multiple spatial scales and multiple taxa is therefore required to provide an overall view of how biodiversity is affected by urbanization. There is currently little consensus on the expected response of total abundance of organisms to urbanization, as both increases and declines have been reported (Chace \& Walsh, 2006; Grimm et al., 2008; Shochat et al., 2010). Increases in abundance could be due to the dominance of a few synanthropic species with superior competitive abilities, enhanced by increased human-mediated food resources and reduced predation (Parris, 2016). Alternatively, the hostile environment imposed by urban structures and the consequent decreased connectivity and size of suitable habitat patches may deplete individuals and species from urban settlements (McKinney, 2008, Saari et al., 2016). Although we could not demonstrate a decline in abundance across the entire set of examined groups in response to local urbanization, significant declines were observed at the group-specific level for ground beetles, ground and web spiders, butterflies and orthopterans, while macro-moths showed a non-significant decreasing trend. Since ground beetles and ground spiders were sampled with pitfall traps, their estimated abundances could potentially be biased by differences in species activity between sites with high and low urbanization, due to variation in local physical parameters, such as temperature. However, in a related study we demonstrated that temperatures are higher at the highly urbanized sampling sites (i.e. UHI-effect, Merckx et al. 2018), thus higher arthropod numbers would have been expected in the urbanized sites, which is opposite to what we observed. Our measurements for these groups are hence highly conservative and thus further strengthen our results. 
The observed declines in diversity support the idea that poor environmental conditions in urban environments decrease the average densities across major organism groups, notably actively dispersing terrestrial arthropods. In contrast, we did not observe declines in abundance along the urbanization gradient for snails, bdelloid rotifers and cladocerans. The latter two groups are small (semi)aquatic passively dispersing organisms that have high dispersal capacities (Fontaneto et al., 2019; Gianuca et al., 2018). As such, they do not need large habitat patches to thrive and, at the same time, being passive dispersers, they cannot avoid cities during their dispersal process. Snails host a number of species that prefer habitats that are abundant in cities, such as patches of soils that are moist because they are covered with debris, stones and other building material.

The obvious decline we observed for terrestrial arthropods parallels the recent reports on global declines of insects, even in areas safeguarded from obvious anthropogenic disturbances (Brooks et al., 2012; Grubisic et al., 2018; Hallmann et al., 2017; Vogel, 2017). Identifying the main causes driving this decline is, however, difficult given the multifaceted influence that urbanization exerts on the environment (Parris, 2016). In particular, the urban-heat-island effect may be put forward as a possible factor driving the observed decline in animal abundance. In fact, temperature increase has recently been identified as one of the dominant factors affecting arthropod numbers, with bottom-up effects towards higher trophic levels feeding on these organisms (Lister \& Garcia, 2018). The abundance response was only observed under local-scale urbanization levels, which is congruent with the urban-heat-island effect that is indeed more pronounced at local spatial scales (Kaiser et al. 2016; Merckx et al., 2018; Brans et al., 2018).

The observed declines in abundance likely represent a rather conservative view on the actual abundance patterns in urban landscapes. To allow comparison between landscapes with high and low urbanization, sampling was restricted to green infrastructures (e.g. grassy/herbaceous vegetation, ponds). In the most urbanized landscapes, such as cities, these sampled green infrastructures might be less common than in rural areas, as they are embedded within built-up areas that likely harbor even lower abundances of the investigated groups. It can thus be expected that the observed declines in terrestrial arthropod abundances are even more pronounced in the most urbanized areas than suggested by our analyses with potential consequences for ecosystem functioning. 
By integrating species richness data from groups that widely differ in diversity, life-history traits and ecological profiles, we showed an overall decrease in total species richness with increasing levels of local and/or landscape-scale urbanization. We demonstrate that sites and landscapes with low urbanization levels harbour a richer species pool compared to areas consisting of a mosaic of urban and non-urban areas. This suggests that the faunal composition of urbanized regions is hardly characterized by species that are absent in less urbanized regions. The significant decrease in abundance for the insect groups also points in this direction, since synanthropic species are expected to become dominant, and might thus increase total abundance in urban areas (Shochat et al., 2010), opposite to what we observed.

When partitioning diversity into its components, the cross-group decline in species richness was most clearly observed at the level of total $(\gamma)$ diversity at both local and landscape scales. However, we found strong differences among the animal groups with respect to the diversity component that was most strongly affected, with significant trends either at $\alpha$ (e.g. web spiders, butterflies) or $\beta$ (e.g. ground beetles, orthopterans) level. Thus, although the overall declining trend of total diversity summarizes the decline across all groups and all diversity components (Crist et al., 2003), the differential response of each group points to the ecological and scaledependent complexity of metacommunity responses to urbanization (Chace \& Walsh, 2006; Hill et al., 2017; Luck \& Smallbones, 2010; Leibold \& Chase, 2017; McKinney, 2008).

For all diversity components we observed a significant decrease for at least one of the examined groups, thus demonstrating that both local species loss ( $\alpha$-diversity) and biotic homogenization $(\beta$ diversity) at all spatial levels may potentially contribute to a decrease in total species richness.

For some groups, such as macro-moths, diversity components declined at multiple spatial scales. For instance, local macro-moth communities are not only impoverished within sites located within urban landscapes, but they are also highly homogeneous among sites within urban landscapes. We further detected biotic homogenization at the largest spatial scale (i.e. across urban landscapes) for ground beetles, ground spiders and orthopterans, and across groups. This suggests that more homogeneous environmental conditions of urbanized areas may filter ecologically and taxonomically similar species from the total species pool (Baldock et al., 2015; Ferenc et al., 2014; La Sorte et al., 2014; McKinney, 2006; but see Brice et al., 2017 and Knop, 2016 for contrasting results). The strong homogenizing effect of urban environments and landscapes has been most 
clearly demonstrated by shifts in community life-history traits in response to urbanization (Concepción et al., 2016; Croci et al. 2008; Knop, 2016; McCune \& Vellend, 2013; Merckx et al., 2018; Penone et al., 2013). For instance, elsewhere we demonstrated how urbanization causes a clear depletion of ground beetle, butterfly and macro-moth species with poor dispersal capacity (Piano et al., 2017; Merckx \& Van Dyck, 2019). Although convergence of biotic communities in urban environments has been shown to be more consistent at the level of community trait values compared to at the taxonomic level (Brans et al., 2017; Gianuca et al., 2018), the results presented here demonstrate that urbanization may not only decrease diversity in functional groups, but also at the level of species richness itself.

Rarefying species richness generally resulted in less strong urbanization effects, in particular at the local scale. We showed that groups with a strong decline in abundance, like orthopterans and butterflies, showed a concomitant decline in local species richness. This suggests that the decrease in local species richness with increasing urbanization might, at least partly, be driven by a sampling effect due the decrease in individual abundances and less so by changes in the local species pool and/or evenness of local communities (Chase \& Knight, 2013). However, although we rarefied richness to the lowest number of individuals within each group, this procedure could potentially lead to the comparison of different points in the rarefaction curves among urbanization categories, e.g. the end of the curve (total richness in the regional pool) in highly urbanized sites against the base of the curve (evenness) in sites with low urbanization (McGlinn et al., 2019). Therefore, one must cautiously interpret the decrease in local $(\alpha)$ species richness as a mere sampling effect. Alternatively, rarefying species richness resulted in a stronger effect of local urbanization on variation in species composition among plots, with ground beetles, ground spiders, orthopterans, snails and bdelloid rotifers all showing significant decreases in beta diversity. Only for butterflies we observed positive effects of local urbanization on beta diversity.

Our sampling design did not allow to explicitly test whether urban plots have a different overall i.e. across habitats - species richness compared to less urbanized plots, as we sampled the same habitat type within examined groups. It has been proposed that cities may sustain high levels of biodiversity, playing an important role in the conservation of global biodiversity and threatened species (Beninde, Veith \& Hochkirch, 2015; Ives et al., 2016; Aronson et al., 2017) due to their habitat heterogeneity that allows species with different habitat preferences to co-exist on small spatial scales (Aronson et al., 2017). In other words, cities host several different habitat types (e.g. 
ruderal habitats, grasslands, wooded areas, ...) within smaller areas compared to natural landscapes, thus increasing the number of species per unit area. However, comparisons across habitats primarily reflect the change in species number per unit area without providing clear information on loss of species within each habitat. We could thus reveal that urbanization impoverishes the fauna within habitat patches and, consequently, that future loss of species due to urbanization is to be expected. This was further suggested by the higher number of species in more natural landscapes compared to landscapes composed of a mosaic of subplots with high and low urbanization. It also indicates that urban environments hardly contain species that are not found outside the urban areas.

Overall, by applying a multi-scale approach across multiple animal groups, we demonstrated a negative overall effect of urbanization on insect abundance and diversity of a range of terrestrial and (semi)aquatic taxa. In particular, we highlighted how passively dispersing taxa tend to be less sensitive to urbanization than actively dispersing taxa. Further investigations should be performed to better understand the mechanisms behind this pattern. Furthermore, our results suggest that urbanization could exert a strong impact on ecosystem functioning and services, as it negatively affects groups that play a central role in a variety of ecological processes, like nutrient cycling (e.g. snails, butterflies, orthopterans and macro-moths), pollination (e.g. butterflies and macromoths), predation (ground beetles, ground and web spiders) and grazing (cladocerans). However, we also highlight that the responses to urbanization strongly depend on the examined group, scale of urbanization and scale at which diversity is assessed.

Results from our study stress the importance that the preservation of large and connected patches of natural habitats is likely the most effective measure to halt further urbanization-driven biodiversity loss. In fact, we demonstrate that patches embedded within urban areas hardly contribute in the maintenance of species that do not occur outside urban areas, thus urban green spaces likely have only a modest contribution in the maintenance of regional species richness. City planning should therefore prioritize the preservation and enlargement of natural habitat relicts rather than focussing on the design of new green infrastructures. In addition, as biodiversity decline in urban areas is largely driven by the depletion of low dispersive and cold-dwelling species (e.g. Concepción et al., 2015; Merckx \& Van Dyck, 2019; Piano et al., 2017), fragmented and dynamic habitat patches within cities will most likely be colonized by generalist species that would not contribute to increase the size of the regional species pool. Avoiding the expansion of 
urban regions, as well as preserving and expanding relict habitats within urban areas, combined with the development of green infrastructures, is therefore the most optimal solution to preserve biodiversity within cities.

\section{Acknowledgements}

This research has been funded by the Interuniversity Attraction Poles Programme Phase VII (P07/4) initiated by the Belgian Science Policy Office. Chantal Van Nieuwenhove and Pieter Vantieghem are gratefully acknowledged for sorting out the large amount of pitfall samples. We thank Aurélien Kaiser for his contribution to the sampling of butterflies and orthopterans, Edwin van den Berg for counting and identifying species in the zooplankton samples, Jasper Dierick for the sampling and identification of web spiders, and Marc Van Kerckvoorde and Marc Hanssen for the identification of ground beetles and snails respectively. FTTH was supported by the Science without Borders program [process number: 45968/2012-1] of Conselho Nacional de Desenvolvimento Científico e Tecnológico - Brazil. The authors declare no conflicts of interest.

\section{Data sharing and data accessibility}

The data that support the findings of this study are available from the corresponding author upon reasonable request. 


\section{BIBLIOGRAPHY}

Agresti, A. (1996). An introduction to categorical data analysis. Wiley, New York, US.

Anderson, M. J., Crist, T. O., Chase, J. M., Vellend, M., Inouye, B. D., Freestone, A. L., Sanders, N. J., Cornell, H. V., Comita, L. S., Davies, K. F., Harrison, S. P., Kraft, N. J. B., Stegen, J. C., \& Swenson, N. J. (2011). Navigating the multiple meanings of $\beta$ diversity: a roadmap for the practicing ecologist. Ecology Letters, 14(1), 19-28. https://doi.org/10.1111/j.14610248.2010.01552.x

Aronson, M. F., La Sorte, F. A., Nilon, C. H., Katti, M., Goddard, M. A., Lepczyk, C. A., Warren, P. S., Williams, N. S. G., Cilliers, S., Clarckson, B., Dobbs, C., Dolan, R., Hedblom, M., Klotz, S., Kooijmans, J. L., Kühn, I., MacGregor-Fors, I., McDonnell, M., Mörtberg, U., Pyšek, P., Siebert, S., Sushinsky, J., Werner, P., \& Winter, M. (2014). A global analysis of the impacts of urbanization on bird and plant diversity reveals key anthropogenic drivers. Proceeding of the Royal Society B, 281(1780), 20133330. https://doi.org/10.1098/rspb.2013.3330

Aronson, M.F.J, Lepczyk, C.A., Evans, K.L., Goddard, M.A., Lerman, S.B., MacIvor, J.S., Nilon, C.H. \& Vargo, T. (2017). Biodiversity in the city: key challenges for urban green space management. Frontiers in Ecology and the Environment, 15, 189-196. https://doi.org/10.1002/fee. 1480

Baldock, K. C., Goddard, M. A., Hicks, D. M., Kunin, W. E., Mitschunas, N., Osgathorpe, L. M., Potts, S. G., Robertson, K. M., Scott, A. V., Stone, G. N., Vaughan, I. P., \& Memmott, J. (2015). Where is the UK's pollinator biodiversity? The importance of urban areas for flower-visiting insects. Proceeding of the Royal Society B, 282(1803), 20142849. https://doi.org/10.1098/rspb.2014.2849

Bates, A. J., Sadler, J. P., Fairbrass, A. J., Falk, S. J., Hale, J. D., \& Matthews, T. J. (2011). Changing bee and hoverfly pollinator assemblages along an urban-rural gradient. PloS one, 6(8), e23459. https://doi.org/10.1371/journal.pone.0023459

Beninde, J., Veith, M. \& Hochkirch, A. (2015). Biodiversity in cities needs space: a meta-analysis of factors determining intra-urban biodiversity variation. Ecology Letters, 18, 581-592. https://doi.org/10.1111/ele.12427 
Bink, F. A. (1992). Ecologische atlas van de Dagvlinders van Noordwest-Europa. Schuyt \& Co, Haarlem, The Netherlands, $512 \mathrm{pp}$.

Boeken, M., Desender, K., Drost, B., van Gijzen, T., Koese, B., Muilvijk, J., Turin, H., \& Vermeulen, R. (2002). De Loopkevers van Nederland en Vlaanderen (Coleoptera: Carabidae). Stichting Jeugdbondsuitgeverij, Utrecht.

Brans, K. I., Govaert, L., Engelen, J. M., Gianuca, A. T., Souffreau, C., \& De Meester, L. (2017). Eco-evolutionary dynamics in urbanized landscapes: evolution, species sorting and the change in zooplankton body size along urbanization gradients. Philosophical Transactions of the Royal Society B, 372(1712), 20160030. https://doi.org/10.1098/rstb.2016.0030

Brans, K. I., Engelen, J. M., Souffreau, C., \& De Meester, L. (2018). Urban hot-tubs: Local urbanization has profound effects on average and extreme temperatures in ponds. Landscape and Urban Planning, 176, 22-29. https://doi.org/10.1016/j.landurbplan.2018.03.013

Brice, M. H., Pellerin, S., \& Poulin, M. (2017). Does urbanization lead to taxonomic and functional homogenization in riparian forests? Diversity and Distributions, 23(7), 828-840. https://doi.org/10.1111/ddi.12565

Brooks, D. R., Bater, J. E., Clark, S. J., Monteith, D. T., Andrews, C., Corbett, S. J., Beaumont, D. A., \& Chapman, J. W. (2012). Large carabid beetle declines in a United Kingdom monitoring network increases evidence for a widespread loss in insect biodiversity. Journal of Applied Ecology, 49(5), 1009-1019. https://doi.org/10.1111/j.1365-2664.2012.02194.x

Chace, J. F., \& Walsh, J. J. (2006). Urban effects on native avifauna: a review. Landscape and Urban Planning, 74(1), 46-69. https://doi.org/10.1016/j.landurbplan.2004.08.007

Chase, J. M., \& Knight, T. M. (2013). Scale-dependent effect sizes of ecological drivers on biodiversity: why standardised sampling is not enough. Ecology Letters, 16, 17-26. https://doi.org/10.1111/ele.12112

Christie, F. J., \& Hochuli, D. F. (2009). Responses of wasp communities to urbanization: effects on community resilience and species diversity. Journal of Insect Conservation, 13(2), 213-221. https://doi.org/10.1007/s10841-008-9146-5 
Concepción, E. D., Moretti, M., Altermatt, F., Nobis, M. P., \& Obrist, M. K. (2015). Impacts of urbanization on biodiversity: the role of species mobility, degree of specialisation and spatial scale. Oikos, 124, 1571-1582. https://doi.org/10.1111/oik.02166

Concepción, E. D., Götzenberger, L., Nobis, M. P., Bello, F., Obrist, M. K., \& Moretti, M. (2016). Contrasting trait assembly patterns in plant and bird communities along environmental and human-induced land-use gradients. Ecography, $\quad$ 40(6), $\quad$ 753-763. https://doi.org/10.1111/ecog.02121

Crist, T. O., Veech, J. A., Gering, J. C., \& Summerville, K. S. (2003). Partitioning species diversity across landscapes and regions: a hierarchical analysis of $\alpha, \beta$ and $\gamma$ diversity. The American Naturalist, 162(6), 734-743.

Croci, S., Butet, A., \& Clergeau, P. (2008). Does urbanization filter birds on the basis of their biological traits? The Condor, 110(2), 223-240. https://doi.org/10.1525/cond.2008.8409

Donner, J. (1965). Ordnung Bdelloidea. Bestimmungsbücher zur Bodenfauna Europas. AkademieVerlag, Germany, 297 pp.

Duff, A. G. (2016). Beetles of Britain and Ireland. Vol. 4. A.G. Duff Publishing, West Runton, UK, 623 pp.

Egerer, M. H., Arel, C., Otoshi, M. D., Quistberg, R. D., Bichier, P., \& Philpott, S. M. (2017). Urban arthropods respond variably to changes in landscape context and spatial scale. Journal of Urban Ecology 3. https://doi.org/10.1093/jue/jux001

Faeth, S. H., Bang, C., \& Saari, S. (2011). Urban biodiversity: patterns and mechanisms. Annals of the New York Academy of Sciences, 1223(1), 69-81. https://doi.org/10.1111/j.17496632.2010.05925.x

Fahrig, L. (2013). Rethinking patch size and isolation effects: the habitat amount hypothesis. Journal of Biogeography, 40(9), 1649-1663. https://doi.org/10.1111/jbi.12130

Ferenc, M., Sedlacek, O., Fuchs, R., Dinetti, M., Fraissinet, M., \& Storch, D. (2014). Are cities different? Patterns of species richness and beta diversity of urban bird communities and regional 
species assemblages in Europe. Global Ecology and Biogeography, 23, 479-489. https://doi.org/10.1111/geb.12130

Finlay, B. J., Esteban, G. F., Brown, S., Fenchel, T., \& Hoef-Emden, K. (2006). Multiple cosmopolitan ecotypes within a microbial eukaryote morphospecies. Protist, 157(4), 377-390. https://doi.org/10.1016/j.protis.2006.05.012

Flößner, D. (2000). Die Haplopoda und Cladocera (ohne Bosminidae) Mitteleuropas. Backhuys, Netherlands: $140-143$.

Fontaneto, D., Westberg, M., \& Hortal, J. (2011). Evidence of weak habitat specialisation in microscopic animals. PLoSone, 6(8), e23969. https://doi.org/10.1371/journal.pone.0023969

Fontaneto D. (2019). Long-distance passive dispersal in microscopic aquatic animals. Movement Ecology, 7(1), 10. https://doi.org/10.1186/s40462-019-0155-7

Gianuca, A. T., Engelen, J., Brans, K. I., Hanashiro, F. T., Vanhamel, M., van den Berg, E. M., Souffreau, C., \& De Meester, L. (2018). Taxonomic, functional and phylogenetic metacommunity ecology of cladoceran zooplankton along urbanization gradients. Ecography, 41(1), 183-194. https://doi.org/10.1111/ecog.02926

Grimm, N. B., Foster, D., Groffman, P., Grove, J. M., Hopkinson, C. S., Nadelhoffer, K. J., Pataki DE, \& Peters, D. P. (2008). The changing landscape: ecosystem responses to urbanization and pollution across climatic and societal gradients. Frontiers in Ecology and the Environment, 6(5), 264-272. https://doi.org/10.1890/070147

Grubisic, M., van Grunsven, R. H. A., Kyba, C. C. M., Manfrin, A., \& Hölker, F. (2018). Insect declines and agroecosystems: does light pollution matter? Annals of Applied Biology, 173(2), 180189. https://doi.org/10.1111/aab.12440

Hallmann, C. A., Sorg, M., Jongejans, E., Siepel, H., Hofland, N., Schwan, H., Stenmans, W., Müller, A., Sumser, H., Hörren, T., Goulson, D., \& de Kroon, H. (2017). More than 75 percent decline over 27 years in total flying insect biomass in protected areas. PLoS one, 12 (10), e0185809. https://doi.org/10.1371/journal.pone.0185809 
He, F.L. \& Legendre, P. (2002). Species diversity patterns derived from species-area models. Ecology 83, 1185-1198. https://doi.org/10.1890/0012-9658(2002)083

Hill, M. J., Biggs, J., Thornhill, I., Briers, R. A., Gledhill, D. G., White, J. C., Wood PJ, \& Hassall, C. (2017). Urban ponds as an aquatic biodiversity resource in modified landscapes. Global Change Biology, 23(3), 986-999. https://doi.org/10.1111/gcb.13401

Hollander, M., \& Wolfe, D. A. (1973). Nonparametric statistical methods. New York: John Wiley and Sons, $503 \mathrm{pp}$.

IBZ (2018). FOD Binnenlandse Zaken, Algemene Directie Instellingen en Bevolking, Rijksregister: http://www.ibz.rrn.fgov.be/fileadmin/user_upload/fr/pop/statistiques/populationbevolking-20170101.pdf.

Ives, C.D., Lentin, P.E., Threfall, C.G., Ikin, K., Shanahan, D.F., Garrard, G.E., Bekessy, S.A., Fuller, R.A., Mumaw, L., Rayner, L., Rowe, R., Valentine, L.E. \& Kendal, D. (2016). Cities are hotspots for threatened species. Global Ecology and Biogeography, 25, 117-126. https://doi.org/10.1111/geb.12404

Jackson, H. B., \& Fahrig, L. (2015). Are ecologists conducting research at the optimal scale? Global Ecology and Biogeography, 24(1), 52-63. https://doi.org/10.1111/geb.12233

Kaiser, A., Merckx, T., \& Van Dyck, H. (2016). The Urban Heat Island and its spatial scale dependent impact on survival and development in butterflies of different thermal sensitivity. Ecology and Evolution, 6(12), 4129-4140. https://doi.org/10.1002/ece3.2166

Knop, E. (2016). Biotic homogenization of three insect groups due to urbanization. Global Change Biology, 22, 228-236. https://doi.org/10.1111/gcb.13091

Lagucki, E., Burdine, J.D., \& McCluney, K.E. (2017). Urbanization alters communities of flying arthropods in parks and gardens of a medium-sized city. PeerJ, 5, e3620. https//doi.org/ 10.7717/peerj.3620.

Lande, R. (1966). Statistics and partitioning of species diversity and similarity among multiple communities. Oikos, 76, 5-13.

La Sorte, F. A., Aronson, M. F., Williams, N. S., Celesti-Grapow, L., Cilliers, S., Clarkson, B. D., 
Dolan, R. W., Hipp, A., Klotz, S., Kühn, I., Pyšek, P., Siebert, S., \& Winter, M. (2014). Beta diversity of urban floras among European and non-European cities. Global Ecology and Biogeography, 23(7), 769-779. https://doi.org/10.1111/geb.12159

Leibold, M. A., \& Chase, J. M. (2017). Metacommunity Ecology (Vol. 59). Princeton University Press.

Lister, B. C., \& Garcia, A. (2018). Climate-driven declines in arthropod abundance restructure a rainforest food web. Proceedings of the National Academy of Sciences of the USA, 115(44), 10397-10406. https://doi.org/10.1073/pnas.1722477115

LRD (2013). Large-scale Reference Database, an object-oriented reference map of Flanders: https://www.agiv.be/international/en/products/grb-en.

Luck, G. W., \& Smallbone, L. T. (2010). Species diversity and urbanization: patterns, drivers and implications. Urban Ecology, 88-119.

Manley, C. (2010). British moths and butterflies: a photographic guide. Bloomsbury Publishing.

Marzluff, J. M. (2017). A decadal review of urban ornithology and a prospectus for the future. Ibis, 159(1), 1-13. https://doi.org/10.1111/ibi.12430

McCune, J. L., \& Vellend, M. (2013). Gains in native species promote biotic homogenization over four decades in a human-dominated landscape. Journal of Ecology, 101(6), 1542-1551. https://doi.org/10.1111/1365-2745.12156

McDonnell, M. J., Pickett, S. T., Groffman, P., Bohlen, P., Pouyat, R. V., Zipperer, W. C., Parmelee R. W., Carreiro M. M., \& Medley, K. (1997). Ecosystem processes along an urban-torural gradient. Urban Ecosystems, 1(1), 21-36. https://doi.org/10.1023/A:1014359024275

McGlinn, D. J., Xiao, X., May, F., Gotelli, N. J., Engel, T., Blowes, S. A., Knight, T. M., Purschke, O., Chase, J. M., \& McGill, B. J. (2019). Measurement of Biodiversity (MoB): A method to separate the scale-dependent effects of species abundance distribution, density, and aggregation on diversity change. Methods in Ecology and Evolution, 10(2), 258-269. https://doi.org/10.1111/2041-210X.13102 
McKinney, M. L. (2006). Urbanization as a major cause of biotic homogenization. Biological Conservation, 127, 247-260. https://doi.org/10.1016/j.biocon.2005.09.005

McKinney, M. L. (2008). Effects of urbanization of species richness: a review of plants and animals. Urban Ecosystems, 11, 161-176. https://doi.org/10.1007/s11252-007-0045-4

Menke, S. B., Guénard, B., Sexton, J. O., Weiser, M. D., Dunn, R. R., \& Silverman, J. (2011). Urban areas may serve as habitat and corridors for dry-adapted, heat tolerant species; an example from ants. Urban Ecosystems, 14(2), 135-163. https://doi.org/10.1007/s11252-010-0150-7

Merckx, T., Souffreau, C., Kaiser, A., Baardsen, L. F., Backeljau, T., Bonte, D., Brans, K. I., Cours, M., Dahirel, M., Debortoli, N., De Wolf, K., Engelen, J. M. T., Fontaneto, D., Gianuca, A. T., Govaert, L., Hendrickx, F., Higuti, J., Lens, L., Martens, K., Matheve, H., Matthysen, E., Piano, E., Sablon, R., Schön, I., Van Donink, K., De Meester, L., \& Van Dyck, H. (2018a). Bodysize shifts in aquatic and terrestrial urban communities. Nature, 558, 113-116. https://doi.org/10.1038/s41586-018-0140-0

Merckx, T., \& Van Dyck, H. (2019). Urbanization-driven homogenization is more pronounced and happens at wider spatial scales in nocturnal and mobile flying insects. Global Ecology and Biogeography. https://doi.org/10.1111/geb.12969

Morelli, F., Benedetti, Y., Ibáñez-Álamo, J. D., Jokimäki, J., Mänd, R., Tryjanowski, P., \& Møller, A. P. (2016). Evidence of evolutionary homogenization of bird communities in urban environments across Europe. Global Ecology and Biogeography, 25(11), 1284-1293. https://doi.org/10.1111/geb.12486

Niemelä, J., \& Kotze, D. J. (2009). Carabid beetle assemblages along urban to rural gradients: a review. Landscape and Urban Planning, 92(2), 65-71. https://doi.org/10.1016/j.landurbplan.2009.05.016

Parris, K.M. (2016). Ecology of Urban Environments. Wiley-Blackwell, Chichester, West Sussex, UK.

Penone, C., Kerbiriou, C., Julien, J. F., Julliard R., Machon, N., \& Viol, I. (2013). Urbanization effect on Orthoptera: which scale matters? Insect Conservation and Diversity, 6(3), 319-327. https://doi.org/10.1111/j.1752-4598.2012.00217.x 
Philpott, S. M., Cotton, J., Bichier, P., Friedrich, R. L., Moorhead, L. C., Uno, S., \& Valdez, M. (2014). Local and landscape drivers of arthropod abundance, richness, and trophic composition in urban habitats. Urban Ecosystems, 17, 513-532. https://doi.org/10.1007/s11252-013-0333-0

Piano, E., De Wolf, K., Bona, F., Bonte, D., Bowler, D. E., Isaia, M., Lens L, Merckx T, Mertens D, van Kerckvoorde M, De Meester, L., \& Hendrickx, F. (2017). Urbanization drives community shifts towards thermophilic and dispersive species at local and landscape scales. Global Change Biology, 23(7), 2554-2564. https://doi.org/10.1111/gcb.13606

Pollard, E., \& Yates, T. (1993). Monitoring butterflies for ecology and conservation: the British butterfly monitoring scheme. Chapman \& Hall, London, UK.

R Development Core Team (2017). R: A language and environment for statistical computing. R Foundation for Statistical Computing, Vienna, Austria. http://www.R-project.org

Ramírez-Restrepo, L., \& MacGregor-Fors, I. (2017). Butterflies in the city: a review of urban diurnal Lepidoptera. Urban Ecosystems, 20(1), 171-182. https://doi.org/10.1007/s11252-0160579-4

Rebele, F. (1994). Ecology and special features of urban ecosystems. Global Ecology and Biogeography Letters, 4, 173-187. https://www.jstor.org/stable/2997649

Rice, W. R., \& Gaines, S. D. (1994). Extending nondirectional heterogeneity tests to evaluate simply ordered alternative hypotheses. Proceedings of the National Academy of Sciences of the USA, 91(1), 225-226. https://doi.org/10.1073/pnas.91.1.225

Roberts, M. J. (2009). The Spiders of Great Britain and Ireland: Compact Edition. Apollo Books, Denmark, 714 pp.

Saari, S., Richter, S., Higgins, M., Oberhofer, M., Jennings, A., \& Faeth, S. H. (2016). Urbanization is not associated with increased abundance or decreased richness of terrestrial animals - dissecting the literature through meta-analysis. Urban Ecosystems, 19, 1251-1264. https://doi.org/10.1007/s11252-016-0549-x

Sánchez-Bayo, F., \& Wyckhuys, K. A. (2019). Worldwide decline of the entomofauna: A review of its drivers. Biological Conservation, 232, 8-27. https://doi.org/10.1016/j.biocon.2019.01.020 
Sattler, T., Obrist, M. K., Duelli, P., \& Moretti, M. (2011). Urban arthropod communities: Added value or just a blend of surrounding biodiversity? Landscape and Urban Planning, 103(3-4), 347361. https://doi.org/10.1016/j.landurbplan.2011.08.008

Seto, K. C., Sánchez-Rodríguez, R., \& Fragkias, M. (2010). The new geography of contemporary urbanization and the environment. Annual Review of Environment and Resources, 35, 167-194. https://doi.org/10.1146/annurev-environ-100809-125336

Seto, K. C., Güneralp, B., \& Hutyra, L. R. (2012). Global forecasts of urban expansion to 2030 and direct impacts on biodiversity and carbon pools. Proceedings of the National Academy of Sciences of the USA, 109(40), 16083-16088. https://doi.org/10.1073/pnas.1211658109

Shochat, E., Warren, P. S., Faeth, S. H., McIntyre, N. E., \& Hope, D. (2006). From patterns to emerging processes in mechanistic urban ecology. Trends in Ecology \& Evolution, 21(4), 186-191. https://doi.org/10.1016/j.tree.2005.11.019

Shochat, E., Lerman, S. B., Anderies, J. M., Warren, P. S., Faeth, S. H., \& Nilon, C. H. (2010). Invasion, competition, and biodiversity loss in urban ecosystems. BioScience, 60(3), 199-208. https://doi.org/10.1525/bio.2010.60.3.6

Soininen, J., McDonald, R., \& Hillebrand, H. (2007). The distance decay of similarity in ecological communities. Ecography, 30(1), 3-12. https://doi.org/10.1111/j.09067590.2007.04817.x

Turrini, T., \& Knop, E. (2015). A landscape ecology approach identifies important drivers of urban biodiversity. Global Change Biology, 21(4), 1652-1667. https://doi.org/10.1111/gcb.12825

Vogel, G. (2017). Where have all the insects gone? Science, 356(6338), 576-579.

Wiens, J. A. (1989). Spatial scaling in ecology. Functional Ecology, 3(4), 385-397. https://www.jstor.org/stable/2389612

Xiao, X., McGlinn, D., May F., \& Oliver, C. (2018). mobr: Measurement of Biodiversity in R. R package version 1.0. 
Tables

Table 1 - Test of the response in abundance towards urbanization at local (subplot) and landscape (plot) scale and their interaction. '\% change' for the main effects is the percentage change in abundance in the highest compared to the lowest urbanization level. Significant effects are depicted in bold.

\begin{tabular}{l|lrr|lrr|rr|}
\hline & \multicolumn{3}{|c|}{$\begin{array}{c}\text { Local (subplot) } \\
\text { urbanization effect }\end{array}$} & \multicolumn{2}{c|}{$\begin{array}{c}\text { Landscape (plot) } \\
\text { urbanization effect }\end{array}$} & \multicolumn{2}{c|}{ Interaction } \\
& $F$ & $P$ & $\%$ change & $F$ & $P$ & $\%$ change & $F$ & $P$ \\
\cline { 2 - 9 } Ground beetles & $F_{2,48}=3.26$ & $\mathbf{0 . 0 4 7}$ & $\mathbf{- 3 1 . 3}$ & $F_{2,48}=0.430$ & 0.654 & -10.0 & $F_{4,48}=0.090$ & 0.984 \\
Ground spiders & $F_{2,48}=5.16$ & $\mathbf{0 . 0 0 9}$ & $\mathbf{- 3 6 . 5}$ & $F_{2,48}=2.26$ & 0.116 & +8.1 & $F_{4,48}=1.11$ & 0.363 \\
Web spiders & $F_{2,35}=8.15$ & $\mathbf{0 . 0 0 1}$ & $\mathbf{- 1 9 . 2}$ & $F_{2,35}=0.500$ & 0.613 & -5.1 & $F_{4,35}=1.19$ & 0.332 \\
Macro-moths & $F_{2,12}=1.33$ & 0.3 & -17.5 & $F_{2,12}=2.62$ & 0.114 & -89.7 & $F_{4,12}=0.880$ & 0.506 \\
Butterflies & $F_{2,48}=56.4$ & $\mathbf{0 . 0 0 1}$ & $\mathbf{- 8 5 . 5}$ & $F_{2,48}=0.340$ & 0.71 & -47.9 & $F_{4,48}=3.65$ & $\mathbf{0 . 0 1 1}$ \\
Orthopterans & $F_{2,48}=18.4$ & $\mathbf{0 . 0 0 1}$ & $\mathbf{- 6 7 . 4}$ & $F_{2,48}=0.990$ & 0.38 & -23.0 & $F_{4,48}=1.94$ & 0.119 \\
Snails & $F_{2,48}=0.220$ & 0.8 & -6.8 & $F_{2,48}=0.480$ & 0.624 & +33.3 & $F_{4,48}=0.670$ & 0.617 \\
Bdelloid rotifers & $F_{2,48}=1.68$ & 0.197 & +29.3 & $F_{2,48}=2.90$ & 0.065 & +113.2 & $F_{4,48}=1.70$ & 0.166 \\
Cladocerans & $F_{2,48}=0.61$ & 0.547 & +234.4 & $F_{2,48}=0.11$ & 0.9 & +54.0 & $F_{4,48}=0.36$ & 0.834 \\
\hline
\end{tabular}


Table 2 - Differences in observed (a) and rarefied (b) species richness components across the three urbanization categories. Plus and minus signs indicate an increase and decrease in species richness from the lowest towards the highest urbanization category respectively, while NT indicates that no difference was detected. Asterisks refer to comparisons wherein the intermediate urbanization level showed higher or lower values compared to the low and high urbanized categories. Colour codes refer to significance values (light red/light green/light yellow (light grey in printed version) -/+: $0.05>\mathrm{P}>0.01$, red/green/yellow (medium grey in printed version) --/++: $0.01>\mathrm{P}>0.001$ and dark red/dark green/dark yellow (dark grey in printed version) ---/+++: $\mathrm{P}<$ 0.001). $\bar{\beta}_{P}$ and $\bar{\beta}_{A}$ refer to proportional $\left(\bar{\beta}_{P}=\gamma / \bar{\alpha}\right)$ and additive $\left(\bar{\beta}_{A}=\gamma-\bar{\alpha}\right)$ beta diversity, respectively, wherein $\bar{\beta}_{P}$ expresses how much the richness at plot (or regional) level increases compared to the richness at subplot (or plot) level, while $\bar{\beta}_{A}$ expresses the absolute increase in number of species between these two sampling levels.

\begin{tabular}{|c|c|c|c|c|c|c|c|c|c|c|c|}
\hline \multirow[t]{2}{*}{$a$} & \multicolumn{4}{|c|}{ Local urbanization } & \multicolumn{7}{|c|}{ Landscape urbanization } \\
\hline & $A$ & $\boldsymbol{\beta}_{P}$ & $\boldsymbol{\beta}_{A}$ & $\Gamma$ & $\alpha$ & $\beta_{P, \text { within }}$ & $\boldsymbol{\beta}_{A, \text { within }}$ & $\gamma_{w i t h i n}$ & $\beta_{P, \text { among }}$ & $\beta_{A, \text { among }}$ & $\gamma$ \\
\hline Ground beetles & - & - & --- & - & - & + & + & - & + & --- & - \\
\hline Ground spiders & - & + & - & - & - & - & - & - & - & - & - \\
\hline Web spiders & - & + & - & - & - & + & - & - & + & + & NT \\
\hline Macro-moths & - & + & + & + & -- & - & - & - & + & - & - \\
\hline Butterflies & -- & ++ & + & - & - & + & - & - & - & - & - \\
\hline Orthopterans & - & - & - & - & - & + & + & NT & -- & --- & - \\
\hline Snails & - & + & --- & - & + & + & + & + & - & - & - \\
\hline $\begin{array}{c}\text { Bdelloid } \\
\text { rotifers }\end{array}$ & + & + & + & + & - & + & + & + & - & - & - \\
\hline Cladocerans & + & + & ---* & - & + & - & - & NT & + & + & + \\
\hline Across groups & - & + & - & - & - & + & - & - & - & - & -- \\
\hline \multirow{2}{*}{$\boldsymbol{b}$} & \multicolumn{4}{|c|}{ Local urbanization } & \multicolumn{7}{|c|}{ Landscape urbanization } \\
\hline & $\alpha$ & $\boldsymbol{\beta}_{P}$ & $\overline{\beta_{A}}$ & $\Gamma$ & $\alpha$ & $\beta_{P, \text { within }}$ & $\boldsymbol{\beta}_{A, \text { within }}$ & $\gamma_{\text {within }}$ & $\overline{\beta_{P, \text { among }}}$ & $\overline{\beta_{A, \text { among }}}$ & $\gamma$ \\
\hline Ground beetles & - & - & - & - & - & + & + & $\overline{--}$ & + & $--{ }^{*}$ & $-*$ \\
\hline Ground spiders & NT & NT & - & NT & - & + & - & - & - & $---*$ & - \\
\hline Web spiders & - & NT & - & - & -- & NT & - & - & + & + & NT \\
\hline
\end{tabular}




\begin{tabular}{|c|c|c|c|c|c|c|c|c|c|c|c|}
\hline Macro-moths & + & + & $+++^{*}$ & + & - & - & - & - & + & - & NT \\
\hline Butterflies & NT & + & +++ & + & - & $\mathrm{NT}^{*}$ & + & - & - & NT & - \\
\hline Orthopterans & - & - & --- & - & - & + & + & NT & - & - & - \\
\hline Snails & - & NT & --- & - & + & NT & + & + & - & - & - \\
\hline $\begin{array}{l}\text { Bdelloid } \\
\text { rotifers }\end{array}$ & - & + & --- & + & NT & NT & NT & NT & - & - & - \\
\hline Cladocerans & + & - & --* & - & $+*$ & + & - & + & + & + & + \\
\hline Across groups & - & + & - & - & - & + & - & - & + & - & - \\
\hline
\end{tabular}




\section{Figure captions}

Figure 1 - Map of the study area, in the northern part of Belgium, showing the location of the 27 sampled landscape-scale plots. Colours refer to urbanization categories (green (medium grey in printed version): low urbanization with $<3 \%$ of built-up area; yellow (light grey in printed version): intermediate urbanization with $5 \%-10 \%$ of built-up area; red (dark grey in printed version): high urbanization with $>15 \%$ of built-up area). The plots are divided in $200 \mathrm{~m} \times 200 \mathrm{~m}$ subplots, to which the same colour code used for the plots is assigned. Subplots characterized by urbanization values intermediate between these three classes are indicated in light green and orange. Within each plot, a subplot belonging to the low, intermediate and high urbanization category was selected as sampling sites.

Figure 2 - Schematic overview of the calculated diversity components to test the effect of urbanization at local scale (a; $200 \mathrm{~m}$ x $200 \mathrm{~m})$ and landscape scale (b; $3 \mathrm{~km}$ x $3 \mathrm{~km})$ (low = green (medium grey in printed version), intermediate = yellow (light grey in printed version), and high = red (dark grey in printed version)). Only the comparisons between low and high urbanization levels are shown.

Figure 3 - Abundances $(\mathrm{N})$ of the nine examined groups in response to local- (subplot) and landscape-scale (plot) urbanization levels. Labels at the $\mathrm{X}$-axis represent the degree of urbanization at the landscape scale. Y-axis scale varies among groups and is log10-transformed, except for web spiders. Colours of the boxplots refer to urbanization levels at the local scale (green $($ medium grey in printed version) $=$ low; yellow (light grey in printed version) $=$ intermediate; red (dark grey in printed version $)=$ high). Boxplots display the median, 25\% and $75 \%$ quartiles and 1.5 interquartile range. The nine animal silhouettes are from PhyloPic (http://www.phylopic.org) and fall under CC-BY 3.0 licences.

Figure 4 - (a) Estimated total number of species for each examined group in nine random samples from five different local/landscape urbanization level combinations using raw data. Y-axis scale is log10-transformed to improve visualization. Pictograms on the x-axis depict (from left to right): (i) subplots with low urbanization in plots with low urbanization (light green square in dark green square); (ii) plots with low urbanization regardless of the degree of local urbanization (light grey square in dark green square); (iii) samples regardless of the degree of local and landscape urbanization level (light grey square in dark grey square); (iv) highly urbanized plots regardless of 
the degree of local urbanization (light grey square in dark red square) and (v) highly urbanized subplots in highly urbanized plots (light red square in dark red square). Asterisks $(*=0.01<\mathrm{P}<$ $0.05, * *=0.01<\mathrm{P}<0.001, * * *=\mathrm{P}<0.001)$ depict results of the directional ordered heterogeneity test rSPc. (b) Correlation between urbanization-related change in abundance versus change in local (open circles) and total (closed circles) observed species richness across examined groups. Values on both axes represent the relative abundance (X-axis) and species richness (Yaxis) in highly urbanized subplots in highly urbanized plots versus those in subplots with low urbanization in plots with low urbanization. Animal silhouettes are from PhyloPic (http://www.phylopic.org) and fall under CC-BY 3.0 licences.

Figure 5 - Total observed diversity (S; Y-axis) partitioning for each examined group and for each of three (a) local- and (b) landscape-scale urbanization levels (green (medium grey in printed version $)=$ low; yellow $($ light grey in printed version $)=$ intermediate; red $($ dark grey in printed version $)=$ high). See Figure 2 for an explanation of the different diversity components. The animal silhouettes are from PhyloPic (http://www.phylopic.org) and fall under CC-BY 3.0 licences. 
(a) Comparison of local-scale urbanization

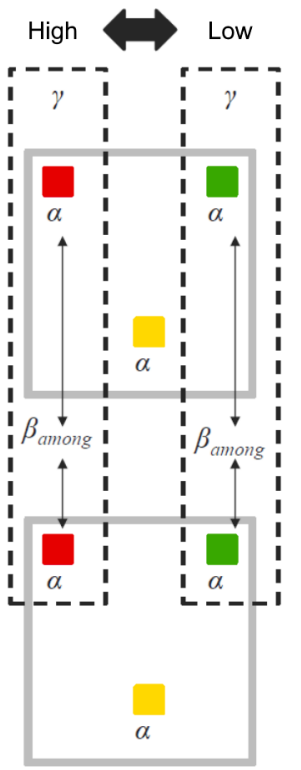

(b) Comparison of landscape-scale urbanization

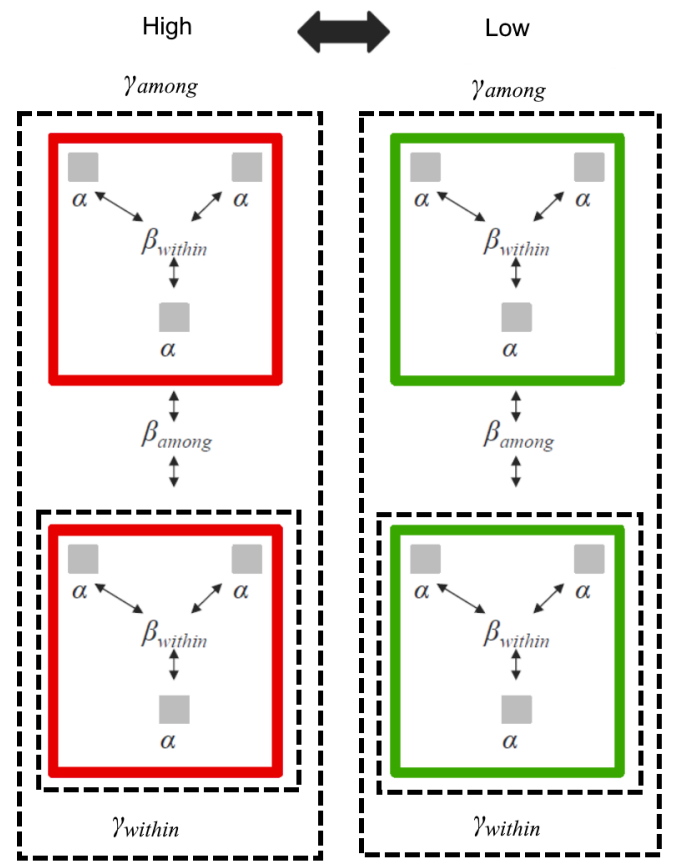

gcb_14934_f2.tif 


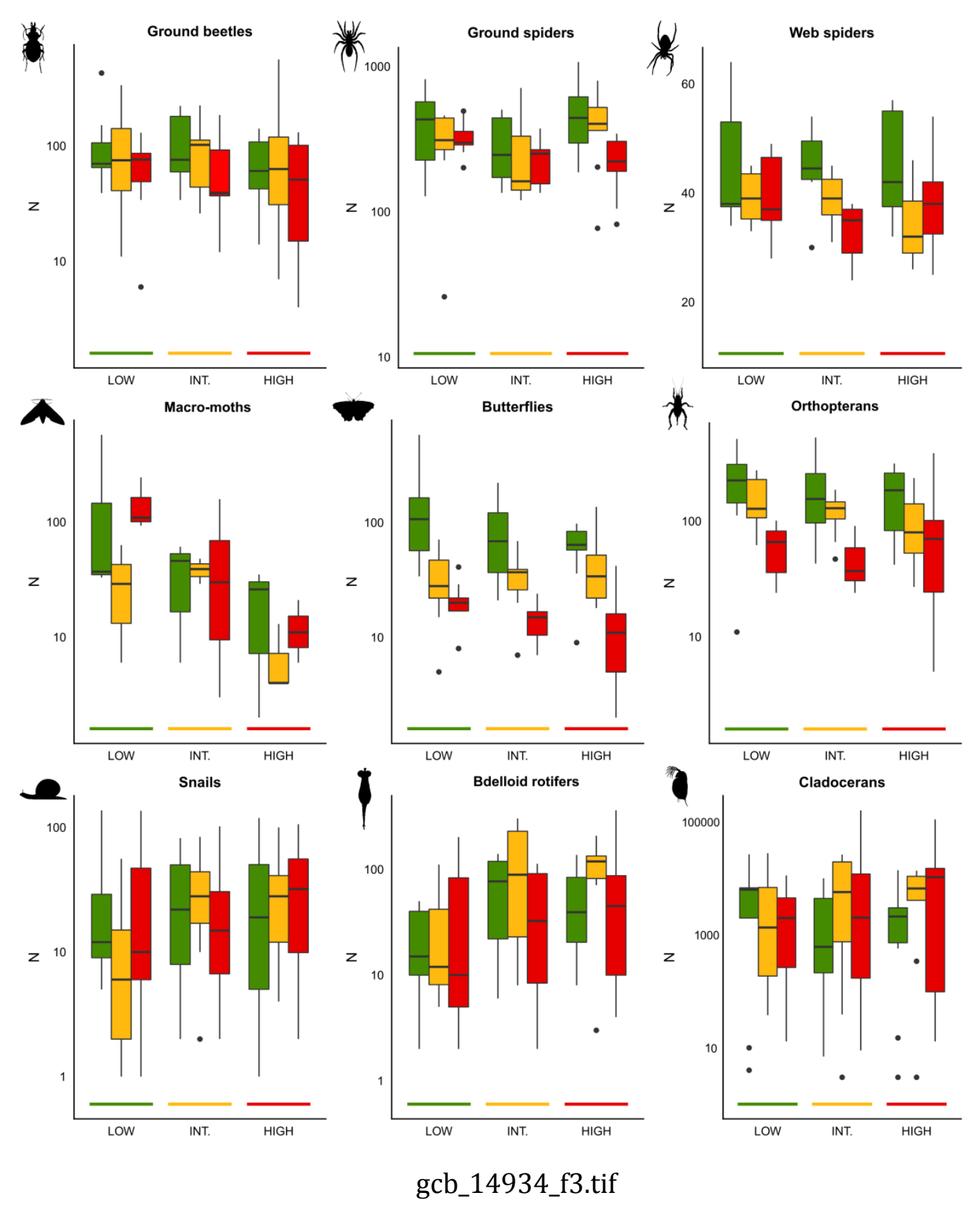


(a)

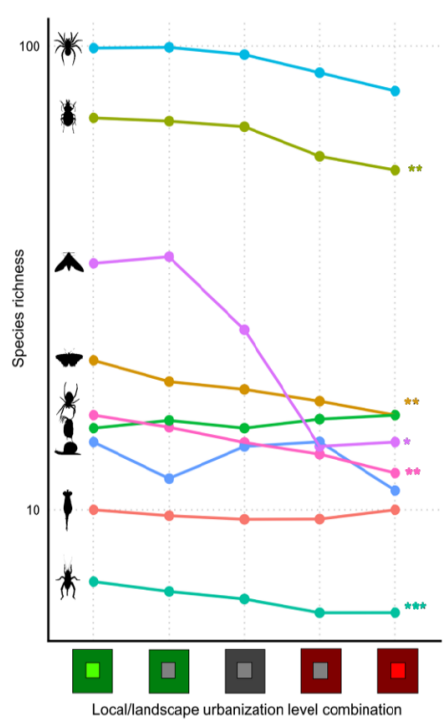

(b)

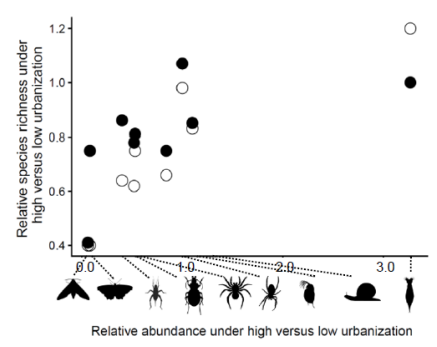

gcb_14934_f4.tif 
(a) Local-scale urbanization

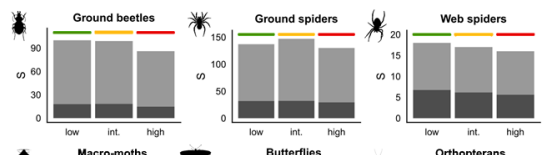

$\left.\begin{array}{l}\beta_{\text {A.among }} \\ \alpha\end{array}\right] \gamma_{\text {among }}$
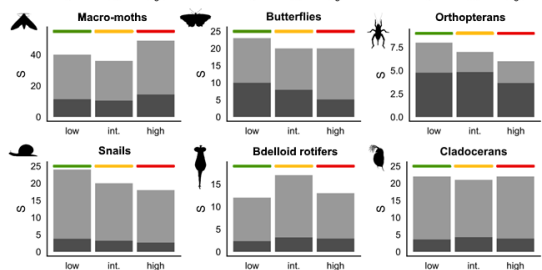

(b) Landscape-scale urbanization
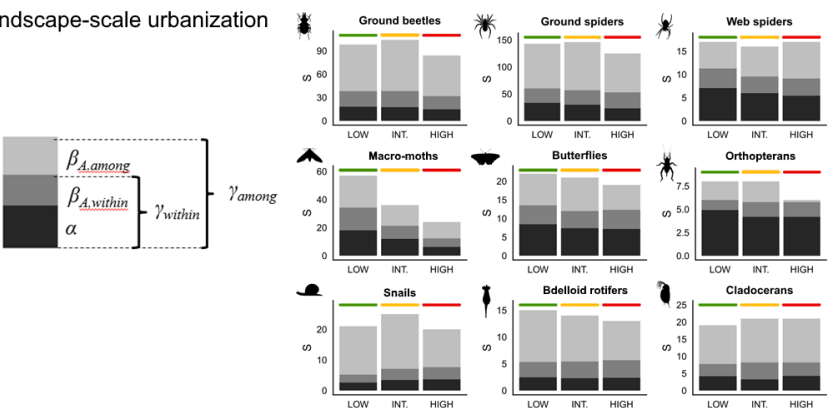

gcb_14934_f5.tif 